\title{
Changes in carbon dioxide emissions and LMDI-based impact factor decomposition: the Xinjiang Uygur autonomous region as a case
}

\author{
Li ZHANG ${ }^{1,2}$, Jun LEI ${ }^{1 *}$, Xuan ZHOU ${ }^{3}$, XiaoLei ZHANG ${ }^{1}$, Wen DONG ${ }^{1}$, Yu YANG ${ }^{2,4}$ \\ ${ }^{1}$ Xinjiang Institute of Ecology and Geography, Chinese Academy of Sciences, Urumqi 830011, China; \\ ${ }^{2}$ University of Chinese Academy of Sciences, Beijing 100049, China; \\ ${ }^{3}$ Department of Mathematics, Jinan University, Guangzhou 510632, China; \\ ${ }^{4}$ Institute of Geographic Sciences and Natural Resources Research, Chinese Academy of Sciences, Beijing 100101, China
}

\begin{abstract}
Studies on carbon dioxide $\left(\mathrm{CO}_{2}\right)$ emissions at provincial level can provide a scientific basis for the optimal use of energy and the formulation of $\mathrm{CO}_{2}$ reduction policies. We studied the variation of $\mathrm{CO}_{2}$ emissions of primary energy consumption and its influencing factors based on data in Xinjiang Uygur autonomous region from 1952 to 2008, which were calculated according to the 2006 IPCC Guidelines for National Greenhouse Gas Inventories. Xinjiang's $\mathrm{CO}_{2}$ emission process from 1952 to 2008 could be divided into five stages according to the growth rates of total amount of $\mathrm{CO}_{2}$ emissions and $\mathrm{CO}_{2}$ emission intensity. The impact factors were quantitatively analyzed using Logarithmic Mean Divisia Index (LMDI) method in each stage. Various factors, including government policies and technological progress related to the role of $\mathrm{CO}_{2}$ emissions, were comprehensively analyzed, and the internal relationships among various factors were clarified. The results show that the contribution rates of various impact factors are different in each stage. Overall, economic growth and energy consumption intensity were the main driving factors for $\mathrm{CO}_{2}$ emissions. Since the implementation of the birth control policy, the driving force of population growth on the increase in $\mathrm{CO}_{2}$ emissions has slowly weakened. The energy consumption intensity was further affected by the industrial structure and energy consumption intensity of primary, secondary and tertiary industries, with the energy consumption intensity of the secondary industries and the proportion of secondary industries being the most important factors affecting the energy consumption intensity. Governmental policies and technological progress were also important factors that affected $\mathrm{CO}_{2}$ emissions.
\end{abstract}

Keywords: $\mathrm{CO}_{2}$ emissions; Logarithmic Mean Divisia Index; economic growth; energy consumption intensity

Citation: Li ZHANG, Jun LEI, Xuan ZHOU, XiaoLei ZHANG, Wen DONG, Yu YANG. 2014. Changes in carbon dioxide emissions and LMDI-based impact factor decomposition: the Xinjiang Uygur autonomous region as a case. Journal of Arid Land, 6(2): 145-155. doi: $10.1007 /$ s40333-013-0242-3

Global warming is one of the most important environmental problems of the time. Strategies and technologies for reducing greenhouse gases, such as $\mathrm{CH}_{4}$ (Zhang and Chen, 2010), $\mathrm{SO}_{2}$ (Carmichael et al., 2002) and $\mathrm{NO}_{\mathrm{x}}$ (Kadian et al., 2007), have been studied. However, carbon dioxide $\left(\mathrm{CO}_{2}\right)$ is considered to be the major greenhouse gas that contributes to global warming (Ma et al., 2011). $\mathrm{CO}_{2}$ emissions produced from the consumption of fossil fuel-based energy sources are the largest source of anthropogenic emissions and the primary source of atmospheric greenhouse gases. The annual $\mathrm{CO}_{2}$ emissions from the consumption of fossil fuels account for approximately $70 \%$ of total atmospheric $\mathrm{CO}_{2}$ emissions (Itousek et al., 1997; Scholes and Noble, 2001). China is the largest producer of $\mathrm{CO}_{2}$ emissions in the world. At the Copenhagen climate conference, the government of China pledged that China would reduce the intensity

*Corresponding author: Jun LEI (Email address: leijun@ms.xjb.ac.cn)

Received 2012-06-01; revised 2013-04-15; accepted 2013-05-20

(C) Xinjiang Institute of Ecology and Geography, Chinese Academy of Sciences, Science Press and Springer-Verlag Berlin Heidelberg 2014 
of its $\mathrm{CO}_{2}$ emissions by $40 \%-45 \%$ from 2005 to 2020 . Therefore, China is facing major pressure regarding the reduction of $\mathrm{CO}_{2}$ emissions. Searching for ways to reduce emissions and accelerating the development of a low-carbon economy are important for China to follow the world developmental trend. Reducing $\mathrm{CO}_{2}$ emissions is also an internal requirement for China to achieve sustainable development.

There have been studies on large-scale areas, such as the Asia-wide emissions of greenhouse gases (Siddiqi, 1995) and global strategy for the reduction of $\mathrm{CO}_{2}$ emissions (Sinyak, 1995). Researches on Chinese $\mathrm{CO}_{2}$ emissions mainly addressed the calculation of total $\mathrm{CO}_{2}$ emissions and spatial patterns of changes in emissions (Zhang et al., 2010; Wang et al., 2011a), $\mathrm{CO}_{2}$ emission driving forces and influencing factors (Fan et al., 2006; Zha et al., 2010), efficient use of energy and $\mathrm{CO}_{2}$ reduction policy (Liu et al., 2010), cross-border transfer of $\mathrm{CO}_{2}$ emissions (Lin and Sun, 2010), and $\mathrm{CO}_{2}$ emissions prediction based on various econometric models (Fan et al., 2007). Some studies have also been performed at the regional level, such as within Taiwan (Chang et al., 2008), Hong Kong (Leung and Lee, 2000), Shanghai (Li et al., 2010), Anhui and Fujian (Wang et al., 2011b), Tianjin (Ma et al., 2011), Shaanxi (Lu et al., 2010), Hebei (Niu et al., 2011) and Shandong (Hong, 2011).

The economy and society of Xinjiang had great progress after the implementation of the strategy of developing western China and the energy consumption in Xinjiang has increased rapidly. Since 2001, Xinjiang's energy consumption has been accelerating. The proportion of Xinjiang's energy consumption to the country's total has been increasing in terms of energy consumption per RMB 10,000 of GDP and Xinjiang's $\mathrm{CO}_{2}$ emissions are much higher than the national average (Yao and Gao, 2011). Xinjiang's $\mathrm{CO}_{2}$ emission status in the country has been highlighted. However, researches about energy consumption and $\mathrm{CO}_{2}$ emissions are no enough. Therefore, this paper is of great theoretical and practical significance. It can enrich studies of $\mathrm{CO}_{2}$ emissions at provincial level and provide a scientific basis for the optimal use of energy and the formulation of $\mathrm{CO}_{2}$ reduction policies in Xinjiang.

\section{Study area}

The Xinjiang Uygur autonomous region, located in Northwest China of Central Eurasia, has a total area of $1,664,900 \mathrm{~km}^{2}$, accounting for $1 / 6$ of China's total land area, and borders eight countries: Russia, Kazakhstan, Kyrgyzstan, Tajikistan, Pakistan, Mongolia, India and Afghanistan (Fig.1). The land border of the region is over $5,600 \mathrm{~km}$ long, representing one quarter of China's land border. Xinjiang has rich coal, oil and natural gas resources. As China's leading energy production and reserve base, Xinjiang holds $1 / 3$ of the oil resources, $34 \%$ of the land natural gas resources and $40 \%$ of the estimated coal reserves in the country. At the end of 2009, the population of the Xinjiang Uygur autonomous region was 21.59 million and Xinjiang's gross domestic product (GDP) was 628.93 billion USD (4,277.05 billion RMB) in 2009.

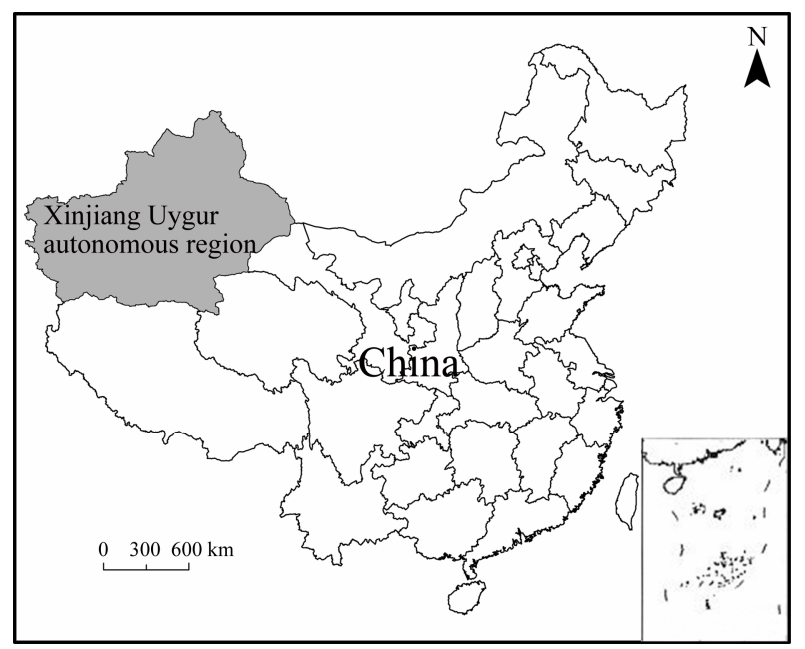

Fig. 1 Location of Xinjiang Uygur autonomous region

\section{Methods and data}

\section{1 $\mathrm{CO}_{2}$ emission calculation}

The $\mathrm{CO}_{2}$ emission of primary energy consumption was calculated according to the 2006 IPCC Guidelines for National Greenhouse Gas Inventories (IPCC, 2006) as follows:

$$
C=\sum_{i=1}^{n} e f_{i} \times E_{i} .
$$

Where $C$ is the amount of $\mathrm{CO}_{2}$ emissions, $E_{i}$ is the $i^{\text {th }}$ type of primary energy consumption according to the standard coal calculation in tons of coal equivalent 
(tce) and $e f_{i}$ is the $i^{\text {th }}$ energy $\mathrm{CO}_{2}$ emission coefficient. The raw data use $J$ as the unit, and the unit of energy is converted into standard coal and the specific conversion factor is one ton standard coal, which is equivalent to 29.3 GJ. The calculated coal, oil and natural gas $\mathrm{CO}_{2}$ emission coefficients were 0.7559 , 0.5857 and $0.4483 \mathrm{t} /$ tce, respectively. Finally, $i$ is the type of energy (coal, oil, natural gas), for which the value is 3 here.

\subsection{Decomposition of $\mathrm{CO}_{2}$ emission impact factors}

For the quantitative analysis of $\mathrm{CO}_{2}$ emission impact factors and further investigation of the role of various impact factors, we used the Logarithmic Mean Divisia Index (LMDI) to decompose the $\mathrm{CO}_{2}$ emissions:

$$
\begin{gathered}
\Delta C=\Delta C_{p}+\Delta C_{i n c}+\Delta C_{i n t}+\Delta C_{s}, \\
\Delta C=C_{t}-C_{0} .
\end{gathered}
$$

Where $\Delta C$ is the total effect of the difference of $\mathrm{CO}_{2}$ emissions between year 0 and year $t$, and consists of four parts: population effect caused by the change of population $\left(\Delta C_{p}\right)$, the income effect caused by change of income $\left(\Delta C_{i n c}\right)$, the energy intensity effect caused by the change of the aggregate energy intensity $\left(\Delta C_{i n t}\right)$, and the fuel share effect caused by the change of the consumption share of fuel type $\left(\Delta C_{s}\right)$.

The expressions for the additive LMDI technique are:

$$
\begin{aligned}
\Delta C_{p} & =\sum_{i=1}^{3} \frac{C_{i, t}-C_{i, 0}}{\ln C_{i, t}-\ln C_{i, 0}} \ln \left(\frac{P_{t}}{P_{0}}\right), \\
\Delta C_{i n c} & =\sum_{i=1}^{3} \frac{C_{i, t}-C_{i, 0}}{\ln C_{i, t}-\ln C_{i, 0}} \ln \left(\frac{i n c_{t}}{i n c_{0}}\right), \\
\Delta C_{i n t} & =\sum_{i=1}^{3} \frac{C_{i, t}-C_{i, 0}}{\ln C_{i, t}-\ln C_{i, 0}} \ln \left(\frac{I_{t}}{I_{0}}\right), \\
\Delta C_{S} & =\sum_{i=1}^{3} \frac{C_{i, t}-C_{i, 0}}{\ln C_{i, t}-\ln C_{i, 0}} \ln \left(\frac{S_{i, t}}{S_{i, 0}}\right),
\end{aligned}
$$

where

$$
\begin{gathered}
S_{i}=\frac{C_{i}}{C}, \\
I=\frac{E}{G D P} \text { is the energy intensity, } \\
i n c=\frac{G D P}{P} \text { is the income. }
\end{gathered}
$$

$C$ is the total $\mathrm{CO}_{2}$ emissions, $C_{i}$ is the $\mathrm{CO}_{2}$ emissions from fuel type $i, P$ is the total population, inc is the per capita income, $I$ is the energy consumption intensity.

\subsection{Decomposition of energy consumption inten- sity factors}

To further explore the factors affecting the intensity of energy consumption, we conducted LMDI decomposition on the energy consumption intensity using the following decomposition formula:

$$
I=\frac{E}{G D P}=\frac{\sum_{j} E_{j}}{\sum_{j} G D P_{j}}=\sum_{j} \frac{E_{j}}{G D P_{j}} \times \frac{G D P_{j}}{\sum G D P_{j}}=\sum_{j} e_{j} \times s_{j},
$$

where $e j$ is the energy consumption intensity, indicating the intensity effect; $s j$ is proportion of the output value as part of the total value of the GDP, indicating the structural effect; and $j$ uses 1, 2 and 3 to represent the primary, secondary and tertiary industries. The total change of energy consumption intensity can be expressed as follows:

$$
\begin{gathered}
\Delta I=\Delta I_{e 1}+\Delta I_{e 2}+\Delta I_{e 3}+\Delta I_{s 1}+\Delta I_{s 2}+\Delta I_{s 3}, \\
\Delta I_{e j}=\frac{W_{j t}-W_{j 0}}{\ln W_{j t}-\ln W_{j 0}} \ln \left(\frac{e_{j t}}{e_{j 0}}\right), \\
\Delta I_{s j}=\frac{W_{j t}-W_{j 0}}{\ln W_{j t}-\ln W_{j 0}} \ln \left(\frac{S_{j t}}{S_{j 0}}\right), \\
W_{j}=e_{j} \times S_{j j} .
\end{gathered}
$$

Where, $\Delta I$, total change of energy consumption intensity between year 0 and year t; $\Delta I_{e 1}$, energy consumption intensity change of primary industries (ECIC PI); $\Delta I_{e 2}$, energy consumption intensity change of secondary industries (ECIC SI); $\Delta I_{e 3}$, energy consumption intensity change of tertiary industries (ECIC TI); $\Delta I_{s 1}$, proportion change of primary industries (PC PI); $\Delta I_{s 2}$, proportion change of secondary industries (PC SI); $\Delta I_{s 3}$, proportion change of tertiary industries (PC TI).

\subsection{Data source}

The data for parameters, such as energy consumption related to coal, oil, natural gas, gross regional product and the total population during 1952-2004, were obtained from "Xinjiang: 50 Years" (Statistical Bureau of Xinjiang Uygur Autonomous Region, 2005); the corresponding data for other years from 2006-2010 came from the "Xinjiang Statistical Yearbook" (Statistical Bureau of Xinjiang Uygur Autonomous Region, 
2006-2010). Data on the energy consumption of primary, secondary and tertiary industries from 19852008 were taken from the Energy Consumption Balance Table in the "Xinjiang Statistical Yearbook of 1989-2010" (Statistical Bureau of Xinjiang Uygur Autonomous Region, 1989-2010) (because there are no data about energy consumption of primary, secondary and tertiary industries before 1985, the calculation of $\mathrm{CO}_{2}$ emissions of all three industries and the energy consumption intensity decomposition were performed for 1985-2008).

\section{Results}

Equation 1 was applied to calculate the $\mathrm{CO}_{2}$ emissions in Xinjiang over the study years and to calculate parameters such as per capita $\mathrm{CO}_{2}$ emissions and the amount of $\mathrm{CO}_{2}$ emissions per RMB 10,000 of GDP.

\subsection{Change in the total amount of $\mathrm{CO}_{2}$ emission}

From 1952-2008, Xinjiang's $\mathrm{CO}_{2}$ emissions from primary energy consumption exhibited an overall increasing trend from $1.23 \times 10^{5}$ to $4.36 \times 10^{7} \mathrm{t}$, which represented a 353 -fold increase over the 56 years. From 1952-1957, Xinjiang's $\mathrm{CO}_{2}$ emissions increased rapidly, with the average annual growth rate reaching 19.08\%. From 1958-1961 (during the "Great Leap Forward" period), a small peak appeared in the amount of Xinjiang's $\mathrm{CO}_{2}$ emissions, and energy consumption exhibited a sharp increase. Following that time, $\mathrm{CO}_{2}$ emissions slowed down until 2001, when Xinjiang's $\mathrm{CO}_{2}$ emissions initiated a new round of rapid growth (Fig. 2).

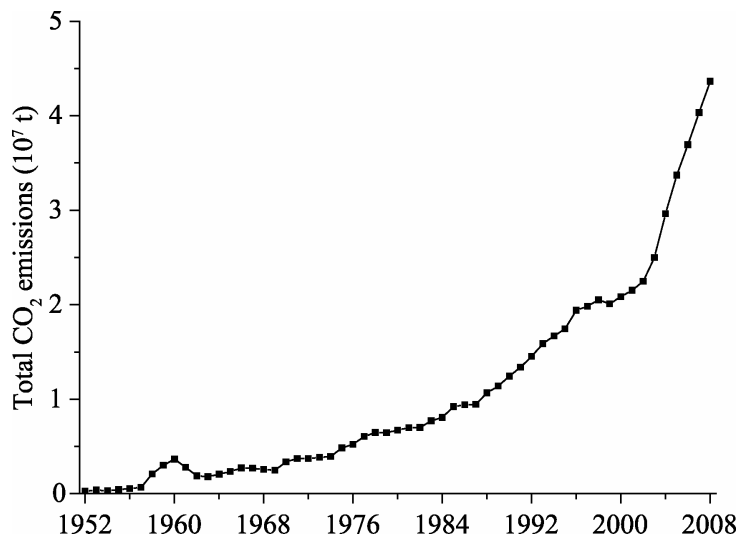

Fig. 2 Changes in total $\mathrm{CO}_{2}$ emissions in Xinjiang from 1952-2008

\subsection{Structural changes in $\mathrm{CO}_{2}$ emission}

The $\mathrm{CO}_{2}$ emission of energy consumption depends on the total energy consumption and energy consumption structure, while the structure of energy consumption mainly depends on a country's (region's) natural resources, energy strategy, economic and technological development level. Coal-rich countries (regions) often use a large proportion of coal in their total energy consumption. It is generally believed that in industrialized societies, the energy consumption structure is changing gradually from a coal-dominated pattern towards the use of oil, natural gas, hydroelectricity, wind and solar energy. The overall energy consumption structure of Xinjiang from 1952-2008 has been developed in accordance with the above route. In 1952, Xinjiang's primary energy consumption was based only on coal and oil in proportions of $82.1 \%$ and $17.9 \%$, respectively. The proportion of coal gradually declined thereafter until 2008, when the proportions of coal, oil, natural gas and water/wind power involved in primary energy consumption were $61.7 \%, 20.3 \%$, $13.1 \%$ and $4.9 \%$, respectively. The energy consumption structure has been continuously optimized, but the coal-dominated energy consumption pattern has not changed. With respect to $\mathrm{CO}_{2}$ emissions from primary energy consumption, the $\mathrm{CO}_{2}$ emissions from coal, oil and natural gas consumption in 2008 were $3.17 \times 10^{7}, 0.8 \times 10^{7}$ and $0.39 \times 10^{7}$ t, respectively (Fig. 3 ), accounting for $72.6 \%, 18.4 \%$ and $9.0 \%$ of total emissions, respectively. Coal consumption remained to be the major source of $\mathrm{CO}_{2}$ emissions.

\section{3 $\mathrm{CO}_{2}$ emission changes in primary, secondary and tertiary industries}

Because there are no detailed data on coal, oil and natural gas energy consumption in primary, secondary and tertiary industries for calculating the $\mathrm{CO}_{2}$ emissions from all three industries and consumption related to daily life, the energy consumption of all three industries and daily life consumption (calculated in standard coal) were multiplied by the $\mathrm{CO}_{2}$ emission coefficient for Xinjiang's energy consumption in that particular year (the total $\mathrm{CO}_{2}$ emissions in that year divided by the amount of energy consumption), which provided the $\mathrm{CO}_{2}$ emissions of all three industries and daily life consumption over the years. 


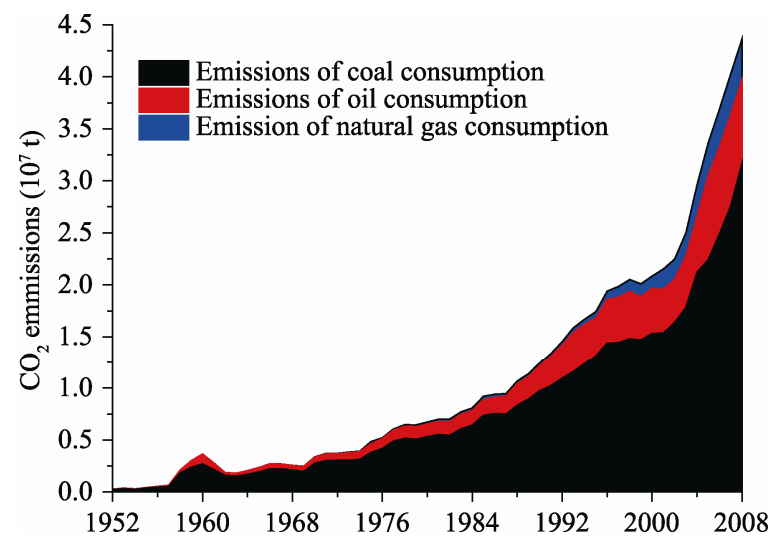

Fig. 3 Changes in $\mathrm{CO}_{2}$ emissions from coal, oil, natural gas consumption in Xinjiang from 1952-2008

Since $1985, \mathrm{CO}_{2}$ emissions from secondary industries have been in a dominant position in the total $\mathrm{CO}_{2}$ emissions of primary energy consumption in Xinjiang. The proportion showed an increasing trend (Fig. 4), from $51.1 \%$ in 1985 to $67.6 \%$ in 2008 , similar to the trend of the proportions of production value in secondary industries (increasing from $36 \%$ to $49 \%$ over the same period). This trend indicates that in the rapid industrialization and developmental stage under Xinjiang's economical level, the secondary industries are still associated with the majority of industrial energy consumption and $\mathrm{CO}_{2}$ emissions.

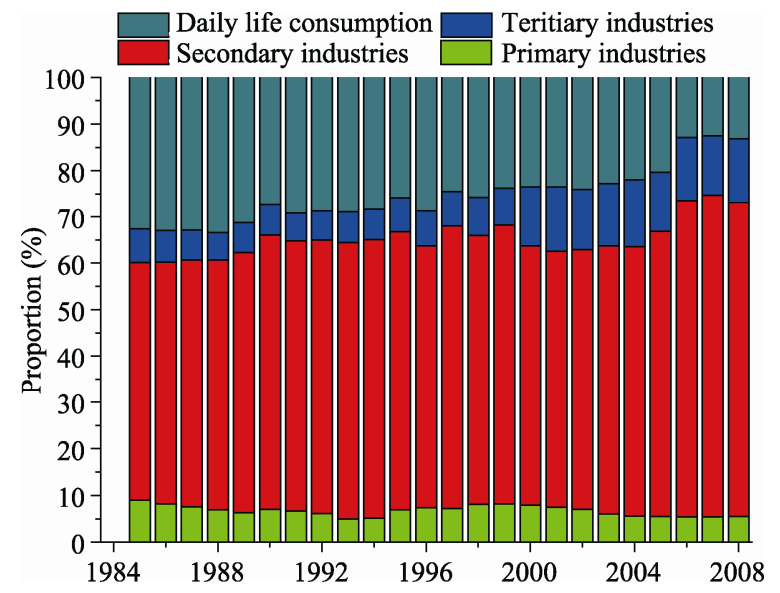

Fig. 4 Proportion changes in $\mathrm{CO}_{2}$ emissions of Xinjiang's primary, secondary and tertiary industries during 1985-2008

\section{4 $\mathrm{CO}_{2}$ emission intensity}

Per capita $\mathrm{CO}_{2}$ emissions increased from $0.06 \mathrm{t} /$ person in 1952 to $2.05 \mathrm{t} /$ person in 2008 , which is equivalent to a 35 -fold increase over 56 years. The $\mathrm{CO}_{2}$ emission levels per RMB 10,000 of GDP exhibited an inverted $\mathrm{V}$-shaped curve, first increasing, then decreasing (ex- cluding the abnormal values of the 4 years from 1958-1961), with the inflection point appearing before and after 1978 (Fig. 5). The increase of per capita $\mathrm{CO}_{2}$ emissions was mainly because of the improvement of people's living standards that caused the increase of per capital energy consumption. With the development of science and technology and the optimization of industrial structure, the energy utilization efficiency improved continuously, so that the $\mathrm{CO}_{2}$ emission level per RMB 10,000 of GDP was reduced.

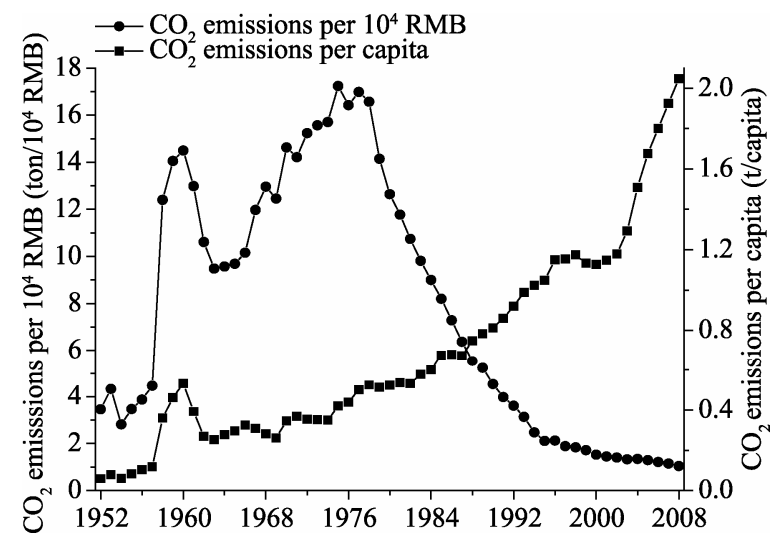

Fig. 5 Changes in Xinjiang's $\mathrm{CO}_{2}$ emissions per RMB 10,000 of GDP and per capita $\mathrm{CO}_{2}$ emissions during 1952-2008

Based on a comparison of the $\mathrm{CO}_{2}$ emission intensities of the different classes of industries $\left(\mathrm{CO}_{2}\right.$ emission amount per RMB 10,000 of GDP), we found that the $\mathrm{CO}_{2}$ emission intensity of secondary industries was significantly higher than those of tertiary industries and primary industries. From 1985-2008, the $\mathrm{CO}_{2}$ emission intensity of secondary industries declined greatly, but it remained much higher than those of other industries (Fig. 6).

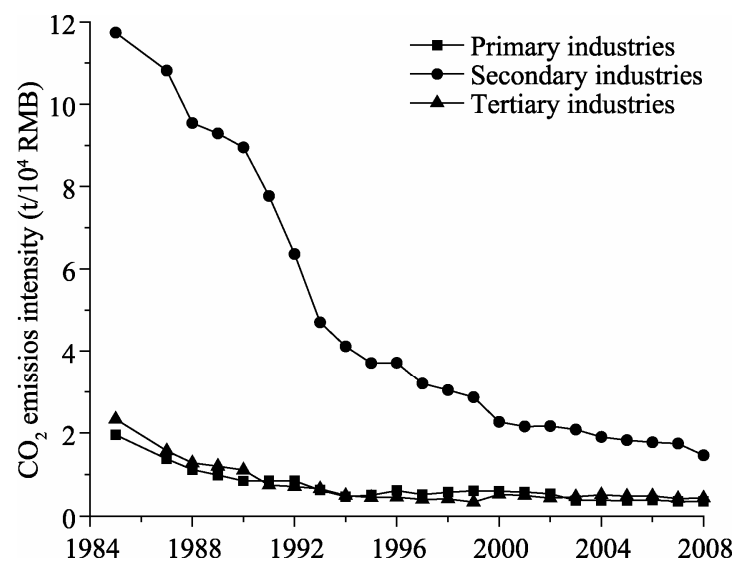

Fig. 6 Changes in $\mathrm{CO}_{2}$ emission intensity of primary, secondary and tertiary industries during 1985-2008 
Table 1 Index values of the evaluation phase of the different $\mathrm{CO}_{2}$ emission stages

\begin{tabular}{cccccc}
\hline & $\begin{array}{c}\text { Stage 1 } \\
(1950-1957)\end{array}$ & $\begin{array}{c}\text { Stage 2 } \\
(1958-1961)\end{array}$ & $\begin{array}{c}\text { Stage 3 } \\
(1962-1978)\end{array}$ & $\begin{array}{c}\text { Stage 4 } \\
(1979-2000)\end{array}$ & $\begin{array}{c}\text { Stage 5 } \\
(2001-2008)\end{array}$ \\
\cline { 2 - 6 } Evaluation index & $\begin{array}{c}\text { National economy } \\
\text { recovery period }\end{array}$ & $\begin{array}{c}\text { Great Leap For- } \\
\text { ward }\end{array}$ & $\begin{array}{c}\text { Cultural Revolu- } \\
\text { tion }\end{array}$ & $\begin{array}{c}\text { Reform and open- } \\
\text { ing-up }\end{array}$ & Western China development \\
\hline $\begin{array}{c}\text { Average annual GDP growth rate } \\
(\%)\end{array}$ & 13.15 & 8.29 & 5.07 & 17.56 & 15.94 \\
$\begin{array}{c}\text { Average annual growth rate of } \\
\begin{array}{c}\mathrm{CO}_{2} \text { emissions (\%) } \\
\text { Average annual growth rate of } \\
\mathrm{CO}_{2} \text { emissions per RMB 10,000 } \\
\text { GDP (\%) }\end{array}\end{array}$ & 19.08 & 43.6 & 8.03 & 5.74 & 10.63 \\
$\begin{array}{c}\text { Average annual growth rate of } \\
\mathrm{CO}_{2} \text { emissions per capita (\%) }\end{array}$ & 5.24 & 20.57 & 2.83 & -10.05 & -4.58 \\
\hline
\end{tabular}

\subsection{Stages of $\mathrm{CO}_{2}$ emissions}

According to characteristics such as socio-economic developmental status, the growth rate of $\mathrm{CO}_{2}$ emissions and the $\mathrm{CO}_{2}$ emission intensity in Xinjiang since 1952, Xinjiang's $\mathrm{CO}_{2}$ emission process was divided into five stages (Table 1):

Stage 1 (1952-1957): the rapid growth of $\mathrm{CO}_{2}$ emissions during the national economic recovery. In this stage, Xinjiang's economy grew rapidly, with GDP exhibiting an average annual growth rate of $13 \%$. The total $\mathrm{CO}_{2}$ emissions, per capita $\mathrm{CO}_{2}$ emissions and $\mathrm{CO}_{2}$ emissions per RMB 10,000 of GDP were low, but the $\mathrm{CO}_{2}$ emissions increased rapidly, with the average annual growth rate reaching $19.5 \%$.

Stage 2 (1958-1961): inefficient energy utilization and abnormal growth of $\mathrm{CO}_{2}$ emission. This stage corresponded to China's "Great Leap Forward" period. In 1958, after the Beidaihe meeting, a nationwide steel production movement was initiated. However, due to the failure to meet technical specifications, the movement consumed a large amount of energy associated with very low economic benefits, resulting in tremendous waste. $\mathrm{CO}_{2}$ emissions in Xinjiang increased rapidly during this stage, from $6.56 \times 10^{5} \mathrm{t}$ in 1957 to $2.1 \times 10^{6} \mathrm{t}$ in 1958. In 1959 and $1960, \mathrm{CO}_{2}$ emissions continued to increase rapidly. However, in 1961, the emissions began to decrease at the end of the "Great Leap Forward". A brief peak occurred in $\mathrm{CO}_{2}$ emissions per RMB 10,000 of GDP and $\mathrm{CO}_{2}$ emissions per capita during this stage (Fig. 5).

Stage 3 (1962-1978): the slow growth of $\mathrm{CO}_{2}$ emissions with the slow economic growth. This stage corresponded to China's "Cultural Revolution" period, when China's economic development was seriously affected. There was slow economic growth, with an average annual GDP growth rate of only $5.06 \%$ in Xinjiang, and the increase in the rate of total $\mathrm{CO}_{2}$ emissions was $8.03 \%$. The growth rate of per capita $\mathrm{CO}_{2}$ emissions and the average annual growth rate of $\mathrm{CO}_{2}$ emissions per RMB 10,000 of GDP were $4.56 \%$ and $2.83 \%$, respectively.

Stage 4 (1979-2000): the slow growth of $\mathrm{CO}_{2}$ emissions with the rapid economic growth. This stage corresponded to the rapid economic development occurring during China's reform and opening-up period. Since its reform and opening-up, China has undergone a great historical transformation from a closed economy to an open one. China's economy experienced rapid development and Xinjiang's economy also developed rapidly in this good environment. The GDP of Xinjiang increased 25 fold over the 21 years, and the average annual growth rate reached $17.56 \%$. The industrial structure was optimized at the same time. Compared to the rapid growth of GDP, $\mathrm{CO}_{2}$ emissions showed no corresponding growth, with an average annual growth rate of only $5.7 \%$, which was closely related to the adjustment and optimization of the industrial structure in Xinjiang.

Stage 5 (2001-2008): the rapid increase of the economy and $\mathrm{CO}_{2}$ emissions. Since 2001, Xinjiang began to rely on its own mineral resources. Under a series of preferential policies to promote the development of western China, economic progress was achieved in Xinjiang. GDP increased rapidly, with an average annual growth rate of $15.9 \%$. Meanwhile, 
the exploration and development of mineral resources, especially coal, oil and natural gas, further accelerated. The coal chemical industry and petrochemical industry developed rapidly. The economic development associated with the industrialization trend was obvious. The proportion of secondary industrial output value gradually increased from $42.4 \%$ in 2001 to $49.5 \%$ in 2008 , with a corresponding decrease for tertiary industries from $38.2 \%$ to $34 \%$. The growth rate of Xinjiang's $\mathrm{CO}_{2}$ emissions in this stage was relatively fast, with the average annual growth rate reaching $10.6 \%$.

\subsection{Decomposition of $\mathrm{CO}_{2}$ emission impact factors}

To explore the impact factors for $\mathrm{CO}_{2}$ emissions and to study various factors associated with $\mathrm{CO}_{2}$ emissions from Xinjiang in the five stages, we applied Eqs. 2-10 to analyze the amount of $\mathrm{CO}_{2}$ emissions. The effective values and contribution rates of the impact factors for $\mathrm{CO}_{2}$ emissions at different stages were obtained (Fig. 7).

Stage 1 (1952-1957): rapid economic growth was the main reason for the increase in $\mathrm{CO}_{2}$ emissions during this period (the contribution rate reached $50.94 \%$ ). The increases in the energy consumption intensity and the total population also had large impacts on $\mathrm{CO}_{2}$ emissions (the contribution rates were $30.31 \%$ and $20.84 \%$, respectively).

Stage 2 (1958-1961): energy consumption intensity was the most important contribution factor for the increase in the $\mathrm{CO}_{2}$ emission intensity at this time (the contribution rate was $74.09 \%$ ). The economic development exhibited a lower contribution rate to $\mathrm{CO}_{2}$ emissions (the contribution rate was 9.68\%). At this stage, the main reason for the rapid growth of $\mathrm{CO}_{2}$ emissions could be due to the inefficient use of energy.

Stage 3 (1962-1978): rapid population growth was the main driving force for the increase in $\mathrm{CO}_{2}$ emissions during this period (the contribution rate was $46.99 \%)$. Due to the liberal population policy during this time, following the second baby boom in the 1960s and the third baby boom in the 1970s in Xinjiang, the average annual population growth rate increased by $36 \%$. The rapid population growth contributed to the growth in energy consumption, resulting in a rapid increase in $\mathrm{CO}_{2}$ emissions. Following the energy consumption intensity (the contribution rate was $36.71 \%$ ), the effect of economic growth was weak (the contribution rate was $19.13 \%$ ) due to slow economic growth in this stage.

Stage 4 (1979-2000): this was the period of fastest economic growth in Xinjiang. Economic development was the main driving force for the growth in $\mathrm{CO}_{2}$ emissions and showed a strong positive effect (the contribution rate was $258.75 \%$ ). The impact of the energy consumption intensity on the growth in $\mathrm{CO}_{2}$ emissions shifted from positive before 1978 to negative in this period (the contribution rate was $-188.58 \%$ ). The sharp decline in the energy consumption intensity significantly reduced the growth rate of $\mathrm{CO}_{2}$ emissions.

Stage 5 (2001-2008): economic development was still the main driving force for the growth in $\mathrm{CO}_{2}$ emissions (the contribution rate was $127.02 \%$ ). When compared to the strong negative effect during Stage 4, the negative effect of the energy consumption intensity at this stage started to diminish (the contribution rate was $-45.44 \%$ ), which was closely related to the increase in the proportion of secondary industries output during this period (further analysis below). The impact of the energy structure on $\mathrm{CO}_{2}$ emissions was different from the four preceding stages, with a positive effect being observed for the first time (the contribution rate was $1.44 \%$ ). This result was mainly because of the increase in the proportion of coal consumption in the energy consumption structure, indicating that the structure of energy consumption during this period did not develop in a direction conducive to $\mathrm{CO}_{2}$ emission reduction.

Overall, economic development exerted a positive effect on $\mathrm{CO}_{2}$ emissions. Economic growth was the main driving factor for the increase in $\mathrm{CO}_{2}$ emissions. The impact of the energy consumption intensity on $\mathrm{CO}_{2}$ emissions showed a positive effect before 1978 and a negative effect after 1978. The absolute values of the contribution rates at various stages were more than $30 \%$, indicating that the main factor of energy consumption intensity reduction (increase) contributed to $\mathrm{CO}_{2}$ emission reduction (increase). The energy consumption structure showed a negative effect from 
Stage 1 to Stage 4, but the contribution rate was small, indicating that the micro-optimization of the energy consumption structure did not change the pattern dominated by coal and had little effect on $\mathrm{CO}_{2}$ emissions. Population growth exerted a positive effect on the increase of $\mathrm{CO}_{2}$ emissions. It had the most intense impact on $\mathrm{CO}_{2}$ emissions in Stage 3. Because of the implementation of the family planning policy, population growth gradually declined, and the driving force of population growth on the growth of $\mathrm{CO}_{2}$ emissions gradually weakened.

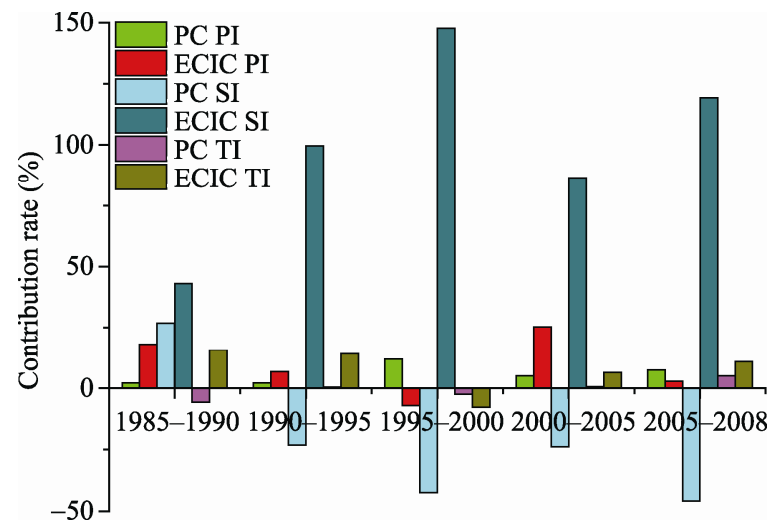

Fig. 7 Contribution rates of $\mathrm{CO}_{2}$ emission decomposition factors. $\mathrm{ECIC} \mathrm{PI,} \mathrm{energy} \mathrm{consumption} \mathrm{intensity} \mathrm{change} \mathrm{of} \mathrm{primary} \mathrm{indus-}$ tries; ECIC SI, energy consumption intensity change of secondary industries; ECIC TI, energy consumption intensity change of tertiary industries; $\mathrm{PC} \mathrm{PI}$, proportion change of primary industries; PC SI, proportion change of secondary industries; PC TI, proportion change of tertiary industries.

\subsection{Decomposition of the impact factors of energy consumption intensity}

The energy consumption intensity was one of the most important impact factors related to $\mathrm{CO}_{2}$ emissions, indicating that further exploration of this factor should be undertaken. Similarly, Eqs. 11-15 were applied to energy consumption intensity to perform residual-free decomposition.

Since 1985, Xinjiang's energy consumption intensity (energy consumption per RMB 10,000 of GDP) has continued to decrease, with the reduced energy intensity in secondary industries contributing the most to this decrease (Fig. 8). The rapid decline in the energy consumption intensity of secondary industries was the most important reason for the reduction in the overall energy consumption intensity; the proportion of the secondary industries output increased (decreased), having a large impact on the increase (decrease) in the energy consumption intensity. From 2001-2008, the contribution rate of the proportion of the secondary industries output to the energy consumption intensity was negative, indicating that since the implementation of the national policy to develop western China in 2001 and because the proportion of

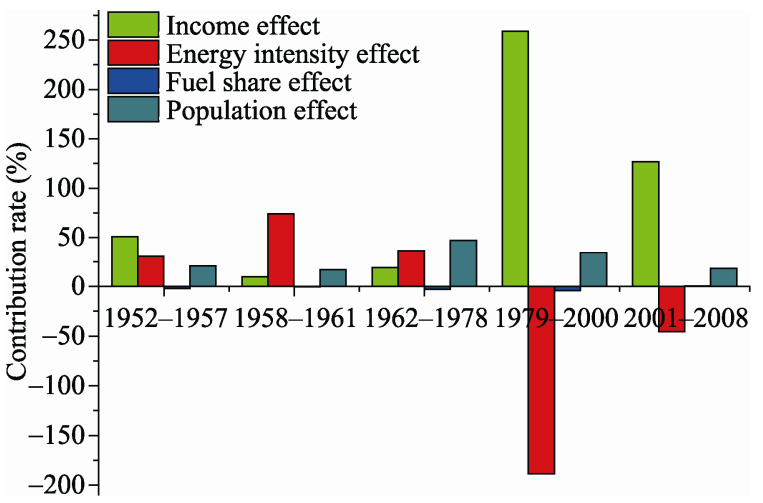

Fig. 8 Contribution rates of various decomposition factors related to the energy intensity

secondary industries output gradually increased, the overall energy consumption intensity was reduced. This was an important reason for the decrease in the negative effect of $\mathrm{CO}_{2}$ emissions related to the Stage 5 overall energy consumption intensity on the amount of $\mathrm{CO}_{2}$ emissions. In summary, the energy consumption intensity of secondary industries and the proportion of the secondary industries output were the major factors that affected the energy consumption intensity. Therefore, improved energy efficiency of secondary industries, continuous optimization of the industrial structure and gradually increased proportion of the total output of tertiary industries increased the overall energy efficiency of the region and, thus, controlled the important parameters related to excessive growth.

\subsection{Comprehensive analysis of impact factors}

Although the application of an LMDI decomposition model was able to quantitatively analyze the effects of various impact factors on $\mathrm{CO}_{2}$ emissions, it ignored the impact of governmental policies and technological advances on $\mathrm{CO}_{2}$ emissions and could not show the relationships between impact factors. Therefore, based on quantitative analysis, we comprehensively ana- 
lyzed the role of various factors on $\mathrm{CO}_{2}$ emissions, including governmental policies and technological progress, as well as clarified the internal relationships between various factors.

Based on our review of Xinjiang's $\mathrm{CO}_{2}$ emission situation since 1952, we observed that the impact of governmental policies on $\mathrm{CO}_{2}$ emissions was very significant. However, the policies did not act directly on $\mathrm{CO}_{2}$ emissions but rather influenced social and economic development, the energy consumption structure, population growth and the industrial structure, which indirectly affect $\mathrm{CO}_{2}$ emissions. This phenomenon is mainly reflected in the following policies. 1) Socio-economic policies: these include policies with major, far-reaching impacts, such as the "Great Leap Forward", the reform and opening-up and the development of western China, which resulted in a historic turning point in the economic development of Xinjiang and caused the $\mathrm{CO}_{2}$ emission situation to change accordingly. Socio-economic development further promoted regional technological progress and the optimization and upgrading of the industrial structure, leading to further declines in the energy consumption intensity and ultimately reducing the increases in the amounts of $\mathrm{CO}_{2}$ emissions. 2) Energy policies: in certain economic and technological conditions, the energy consumption structure at national and large regional scales depends on natural resources, while energy policies had an effect on the energy consumption structure. Although energy policies could not change Xinjiang's fundamental coal-dominated energy consumption patterns in a short-term, through policy guidance, the energy consumption structure has gradually been optimized, and the proportion of low-carbon energy resources in the total energy consumption has continuously increased, thus resulting in the slow growth in $\mathrm{CO}_{2}$ emissions. 3) Population policies: human demand for energy was the direct driving force for the growth of energy consumption. Population growth and improved living standards resulting in increased energy demand per capita could lead to increases in the total energy consumption, and population policies had a direct impact on population growth. 4) Industrial policies: the government affected $\mathrm{CO}_{2}$ emissions through market and administrative mechanisms to guide the industrial structure by optimization and upgrading, decreasing the energy consumption intensity (Fig. 9).

Overall, governmental policies, economic growth and energy consumption intensity were the main driving factors for $\mathrm{CO}_{2}$ emissions. The policies act indirectly on $\mathrm{CO}_{2}$ emissions. However, economic development and energy consumption intensity act directly on $\mathrm{CO}_{2}$ emissions. The rapid growth of China's economy depends on the rapid growth of resource and energy consumption. This is an extensive pattern of economic growth. Therefore, economic growth is the main driving factor for $\mathrm{CO}_{2}$ emissions. The government has noticed this problem and improved energy utilization efficiency by setting out a series of related policies and measures, which decelerated the increase of $\mathrm{CO}_{2}$ emissions.

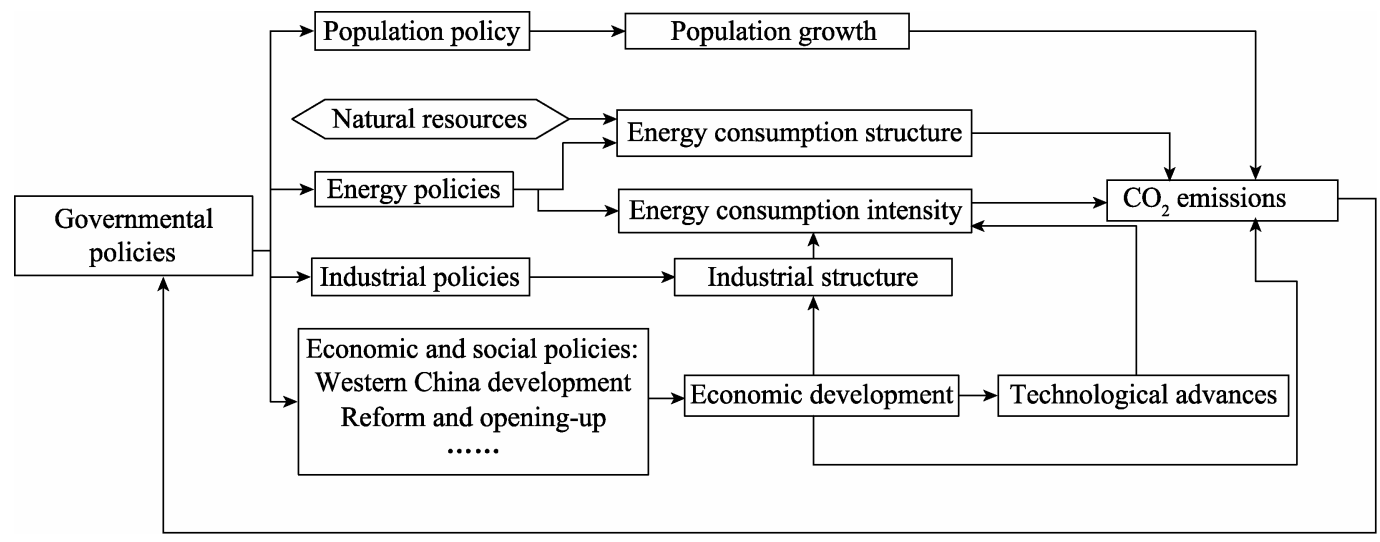

Fig. 9 Diagram of the interaction between $\mathrm{CO}_{2}$ emission impact factors 


\section{Conclusions and suggestions}

Xinjiang's $\mathrm{CO}_{2}$ emissions have gone through five stages, and the contribution rates of various impact factors are different in the five stages. Overall, governmental policies, economic growth and energy consumption intensity were the main driving factors for $\mathrm{CO}_{2}$ emissions. Therefore, making proper policies and decreasing the energy consumption intensity are important measures to achieve the targets of $\mathrm{CO}_{2}$ emission reduction. Xinjiang's coal-dominated energy consumption patterns have not changed considerably, so the energy consumption structure had little impact on $\mathrm{CO}_{2}$ emissions. Since the implementation of the family planning policy, the driving force of population growth on the increase in $\mathrm{CO}_{2}$ emissions has slowly weakened. The energy consumption intensity was further affected by the industrial structure, with the energy consumption intensity and the proportion of the secondary industries being the most important factors.

Governmental policies and technological progress were important factors that affected $\mathrm{CO}_{2}$ emissions. In China, the impacts of policies on energy consumption and $\mathrm{CO}_{2}$ emissions have been very significant. Policies have indirect impacts on $\mathrm{CO}_{2}$ emission generation through affecting social and economic development, the energy consumption structure, population growth and industrial structure; technological progress was promoted by social and economic development and influenced the energy consumption intensity to produce an effect on $\mathrm{CO}_{2}$ emissions.

For the above, we conclude that Xinjiang can reduce $\mathrm{CO}_{2}$ emissions from several respects: Firstly, to integrate the resources of heavy chemical industries and speed up product upgrading, and in addition, energetically develop high and new technology industries and modern service industries, constantly improving the proportion of tertiary industries in the national economy and changing the way of economic development from extensive to intensive as soon as possible. Secondly, to support the development of wind power, solar and biomass energy projects in order to keep sustained growth in the proportion of nonfossil energy resources. Moreover, to make full use of the advantage of abundant natural gas resources in Xinjiang and increase the proportion of natural gas in energy consumption. Thirdly, to increase investments in the advanced energy-saving technologies and to apply innovative technologies to energy exploitation and utilization, vigorously advocating the concept of lowcarbon consumption and green consumption and guiding consumption patterns to a sustainable direction.

\section{Acknowledgements}

This project was funded by the National Natural Science Foundation of China (41101159) and the Western Doctor Project of West Light Foundation of the Chinese Academy of Sciences (XBBS201009).

\section{References}

Carmichael G R, Streets D G, Calori G, et al. 2002. Changing trends in sulfur emissions in Asia: implications for acid deposition, air pollution, and climate. Environmental Science \& Technology, 36(22): 4707-4713.

Chang Y F, Lewis C, Lin S J. 2008. Comprehensive evaluation of industrial $\mathrm{CO}_{2}$ emission (1989-2004) in Taiwan by input-output structural decomposition. Energy Policy, 36(7): 2471-2480.

Eggleston H S, Buendia L, Miwa K, et al. 2006. The 2006 IPCC guidelines for national greenhouse gas inventories. Japan: Institute for Global Environmental Strategies, 11-29[2012-05-01]. http://down.pinggu.org/html/20100611/14645.html.

Fan Y, Liu L C, Wu G, et al. 2006. Analyzing impact factors of $\mathrm{CO}_{2}$ emissions using the STIRPAT model. Environmental Impact Assessment Review, 26(4): 377-395.

Fan Y, Liang Q M, Wei Y M, et al. 2007. A model for China's energy requirements and $\mathrm{CO}_{2}$ emissions analysis. Environmental Modelling \& Software, 22(3): 378-393.

Hong X. 2011. The calculation of carbon emissions of Shandong province and the comparison with the national average. Energy Procedia, 5: 1514-1518.

Itousek P M, Mooney H A, Jane L, et al. 1997. Human domination of earth's ecosystems. Science, 277(25): 494-499.

Kadian R, Dahiya R P, Garg H P. 2007. Energy-related emissions and mitigation opportunities from the household sector in Delhi. Energy Policy, 35(12): 6195-6211.

Leung D Y C, Lee Y T. 2000. Greenhouse gas emissions in Hong Kong. Atmospheric Environment, 34(26): 4487-4498.

Li L, Chen C, Xie S, et al. 2010. Energy demand and carbon emissions under different development scenarios for Shanghai, China. Energy Policy, 38(9): 4797-4807.

Lin B Q, Sun C W. 2010. Evaluating carbon dioxide emissions in 
international trade of China. Energy Policy, 38(1): 613-621.

Liu W D, Zhang L, Wang L M, et al. 2010. A sketch map of low-carbon economic development in China. Geographical Research, 5: $778-788$.

Lu C Y, Zhang X L, He J K. 2010. A CGE analysis to study the impacts of energy investment on economic growth and carbon dioxide emission: a case of Shaanxi province in western China. Energy, 35(11): 4319-4327.

Ma C, Ju M T, Zhang X C, et al. 2011. Energy consumption and carbon emissions in a coastal city in China. Procedia Environmental Sciences, 4: 1-9.

Niu X G, Niu J G, Men D. 2011. Energy consumption and carbon emissions: analysis and prediction - the case of Hebei province in China. Energy Procedia, 5: 2271-92277.

Scholes R J, Noble I R. 2001. Storing Carbon on Land. Science, 29(2): 1012-1013.

Siddiqi T A. 1995. Asia-wide emissions of greenhouse gases. Annual Review of Energy and the Environment, 20(1): 213-232.

Sinyak Y. 1995. Economics of a global strategy for reduction of carbon emissions. International Journal of Environment and Pollution, 5(1): 30-51.

Statistical Bureau of Xinjiang Uygur Autonomous Region. 1989-2010.
Statistical Yearbooks of Xinjiang Uygur Autonomous Region. Beijing: China Statistics Press.

Statistical Bureau of Xinjiang Uygur Autonomous Region. 2005. Statistical Yearbooks of Xinjiang Uygur Autonomous Region from 1955 to 2005. Beijing: China Statistics Press.

Wang S S, Zhou D Q, Zhou P, et al. 2011a. $\mathrm{CO}_{2}$ emissions, energy consumption and economic growth in China: a panel data analysis. Energy Policy, 39(9): 4870-4875.

Wang R, Liu W J, Xiao L S, et al. 2011b. Path towards achieving of China's 2020 carbon emission reduction target-A discussion of low-carbon energy policies at province level. Energy Policy, 39(5): 2740-2747.

Yao L L, Gao Z G. 2011. The role of Xinjiang in low carbon China: challenges and strategy. Finance \& Economics of Xinjiang, 2: 41-44.

Zha D L, Zhou D Q, Zhou P. 2010. Driving forces of residential $\mathrm{CO}_{2}$ emissions in urban and rural China: an index decomposition analysis. Energy Policy, 38(7): 3377-3383.

Zhang B, Chen G Q. 2010. Methane emissions by Chinese economy: inventory and embodiment analysis. Energy Policy, 38(8): 4304-4316.

Zhang L, Huang Y X, Li Y M, et al. 2010. An investigation on spatial changing pattern of $\mathrm{CO}_{2}$ emissions in China. Resources Science, 2: 211-217. 